the proposed treatment. For this to happen, the patient needs to be given the relevant information, to be able to understand and weight it and to state his or her choice. The patient must have the 'capacity' to do this and not be under duress.

White's patient had been given the information and the fact that he was able to withdraw his consent suggests he was not under duress. My concern is whether or not the patient's capacity to give consent was compromised by his illness. There are legal tests of capacity but these are not useful in clinical practice. A further dilemma is posed as, while wanting to respect the autonomy of patients, the alternatives available with respect to consent are perplexing. Many people with serious long-term mental illness cannot give informed consent but treating each under section 3 of the Mental Health Act would swamp the system, might mar therapeutic relationships and is often resisted by other staff.

C. BRABBins, Whiston Hospital, Prescot, Merseyside L35 5DR

\section{Antidepressant prescribing in New Zealand}

Sir: I read with interest Dr Thompson's paper on antidepressant prescribing (Psychiatric Bulletin, August 1994, 18, 461-462). Having worked in the same community team and at the local inpatient unit. I feel the article brought up an interesting point relating to the consultation fee that New Zealand residents pay to see their GP (but not to see a mental health professional).

This fee caused problems in the management of people with mental ill health. People developed a reluctance to visit their GP (often voiced in clinic) with a resultant pressure on GPs to have longer intervals between consultations and therefore having to write prescriptions to cover longer periods. This created problems, especially where there was a suicide risk as the patient could have a larger quantity of medication in his or her possession. There may therefore have been a reluctance to prescribe a therapeutic dose and to opt for a sub-therapeutic prescription. This perversely may leave patients at greater risk as their depression remains untreated. It was also my impression that referrals present earlier in the course of illness which may be a result of the fee. Finally, there was a lack of shared care between the GP and mental health team as a consequence of the reluctance of patients to see their GP, because of the financial burden. This may have a secondary effect of de-skilling the GP.

KEITH R. LINSLEY, St George's Hospital, Morpeth, Northumberland NE61 2NU

\section{Training in a home treatment team}

Sir: Smyth \& Bracken (Psychiatric Bulletin, July 1994, 18, 408-409) describe their training experience in a home treatment team. Having worked as a registrar with the same team I share many of the experiences they describe. I would like to add a few further observations.

Smyth \& Bracken describe how "working without the apparent security of hospital wards initially provoked anxiety." My previous working experience as a junior doctor in various hospital settings had not been free from anxiety. There were worries and uncertainties about patient and staff well-being and safety but more noticeable to me were anxieties provoked by the way 'hospital systems' operate. The need for control and request that the patient should fit into hospital routine are central to treatment within institutions. Behaviour that is unacceptable within these regimes will frequently be interpreted as part of mental illness and result in the increase of control in various forms. My anxieties were related to the fact that I often felt unsure whether 'mental illness' or the 'social context' were the source of a particular presentation.

My working experience with a home treatment team has not given me an altogether different picture of psychiatric illness. Psychotic experiences seen similar whether at home or in hospital. I was, however, struck by the different kinds of relationship that seem possible between patients in their own home environment and the professionals offering support. As a result I have started to look at psychiatric illness in a different light and I have become more aware of the extent to which 'the illness' is a social construct rather than a clear medical entity. This broader view of psychiatric illness has in my case led to a very positive and fulfilling working experience.

IRENE LAMPERT, North Birmingham Mental Health Trust, East Sector, Birmingham B10 9JH

\section{Cardiopulmonary resuscitation}

Sir: The study by McNaughton. Hall \& Stark (Psychiatric Bulletin, July 1994, 18, 403-404), revealing the poor technical proficiency of junior doctors in cardiopulmonary resuscitation (CPR), confirms the fears of many junior doctors who are often the only medical cover for a large number of in-patients. However, the recommendation of the authors that junior doctors receive regular refresher courses in cardio-pulmonary resuscitation is insufficient.

Many psychiatric hospitals are on extremely large sites, while many on-call duties involve covering a number of different sites. It is therefore essential that all clinical staff, especially 